\title{
Insights on Sea Ice Data Assimilation from Perfect Model Observing System Simulation Experiments
}

\author{
Yong-Fei Zhang AND Cecilia M. Bitz \\ Department of Atmospheric Sciences, University of Washington, Seattle, Washington
JefFrey L. ANDERSOn, NANCY COLlins, JONATHAN HENDRicks, Timothy HoAR, AND KEVIN RAEDER \\ IMAGe, CISL, National Center for Atmospheric Research, Boulder, Colorado \\ FRANÇOIS MASSONNET \\ Georges Lemaitre Centre for Earth and Climate Research, Earth and Life Institute, Université Catholique de \\ Louvain, Louvain-la-Neuve, Belgium, and Earth Science Department, Barcelona Supercomputing \\ Center, Barcelona, Spain
}

(Manuscript received 29 December 2017, in final form 17 April 2018)

\begin{abstract}
Simulating Arctic sea ice conditions up to the present and predicting them several months in advance has high stakeholder value, yet remains challenging. Advanced data assimilation (DA) methods combine real observations with model forecasts to produce sea ice reanalyses and accurate initial conditions for sea ice prediction. This study introduces a sea ice DA framework for a sea ice model with a parameterization of the ice thickness distribution by resolving multiple thickness categories. Specifically, the Los Alamos Sea Ice Model, version 5 (CICE5), is integrated with the Data Assimilation Research Testbed (DART). A series of perfect model observing system simulation experiments (OSSEs) are designed to explore DA algorithms within the ensemble Kalman filter (EnKF) and the relative importance of different observation types. This study demonstrates that assimilating sea ice concentration (SIC) observations can effectively remove SIC errors, with the error of total Arctic sea ice area reduced by about $60 \%$ annually. When the impact of SIC observations is strongly localized in space, the error of total volume is also modestly improved. The largest simulation improvements are produced when sea ice thickness (SIT) and SIC are jointly assimilated, with the error of total volume decreased by more than $70 \%$ annually. Assimilating multiyear sea ice concentration (MYI) can reduce error in total volume by more than $50 \%$. Assimilating MYI produces modest improvements in snow depth (errors are reduced by around 16\%), while assimilating SIC and SIT has no obvious influence on snow depth. This study also suggests that different observation types may need different localization distances to optimize DA performance.
\end{abstract}

\section{Introduction}

Significant changes have been observed in the Arctic sea ice extent during the past few decades. Decreasing trends of the total Arctic sea ice extent have been identified in all seasons, and the strongest decline appears in summer (Comiso 2002; Meier et al. 2007; Serreze et al. 2007). While large regional variations exist, most regions have experienced significant declining trends in sea ice extent (Meier et al. 2007). Although the

Corresponding author: Yong-Fei Zhang, yz4362@atmos.uw.edu causes of such trends are varied, warming Arctic temperatures may be a dominant factor as opposed to natural oscillations (Comiso et al. 2008). On the other hand, reduction in sea ice extent is associated with the majority of the warming in the Arctic because of the strong positive ice-temperature feedbacks (Screen and Simmonds 2010) and because sea ice extent also influences other key feedback processes (Po-Chedley et al. 2018). Besides, the Arctic sea ice has also thinned at dramatic rates, as reflected by the strong reductions in the satellite-retrieved sea ice thickness (Kwok and Rothrock 2009) and multiyear ice concentration (Comiso 2012). 
Arctic sea ice attracts particular interest because anomalies in the concentration and thickness have profound influences on human activities such as maritime shipping and subsistence hunting. Sea ice anomalies also exert pressure on wildlife as animals face habitat change. Climate models predict that the decreasing trends will continue and the Arctic Ocean may be ice free in late summer within a few decades, albeit a large intermodel spread exists in how rapidly Arctic sea ice retreats (e.g., Holland et al. 2006; Stroeve et al. 2012).

Predicting sea ice anomalies in space and time is of great importance, especially at seasonal-interannual time scales. Persistence of sea ice anomalies is one of the major sources of sea ice predictability. Persistence is usually defined as the time when the lagged temporal autocorrelation relaxes to 1/e (Lukovich and Barber 2007). The persistence of total Arctic sea ice extent lasts for a few months, depending on season (BlanchardWrigglesworth et al. 2011a; Day et al. 2014a). The persistence of total Arctic sea ice volume is much longer, at several years (Blanchard-Wrigglesworth et al. 2011a). The physical processes involved with the reemergence of sea ice cover are found to extend the predictability limit of sea ice extent up to several years (BlanchardWrigglesworth et al. 2011a,b). Predictability of sea ice concentration (SIC) at the local scale (i.e., about 10-100 km) and sea ice extent at the regional scale (i.e., the scale of seas within the Arctic like the Chukchi or south Beaufort Seas) is similar to the predictability of total Arctic extent (Chevallier et al. 2013; Day et al. 2014a; Bushuk et al. 2017).

The importance of initial conditions in predicting Arctic sea ice from the local to pan-Arctic scale and at seasonal time scales has been investigated or highlighted by previous studies (e.g., Msadek et al. 2014; Day et al. 2014b; Collow et al. 2015; Dirkson et al. 2017). Each of these studies found the benefit of accurately initializing sea ice thickness (SIT) is unequivocal.

Since accurate initial conditions of the sea ice cover, especially SIT, are crucial for seasonal prediction of sea ice, it is necessary to use observations to constrain sea ice initial conditions for predictions. Data assimilation (DA) is a useful technique to combine observations and model forecasts to reconstruct the state of sea ice in the past and provide more accurate initial conditions for sea ice predictions. Fortunately, SIC has been monitored by satellites since the late 1970s. The assimilation of satellite-retrieved observations of SIC exclusively has been shown in a number of coupled sea ice-ocean models to improve SIC forecasts but with little or no improvements in SIT generally (e.g., Lisæter et al. 2003; Lindsay and Zhang 2006; Massonnet et al. 2015; Kimmritz et al. 2018). In contrast, assimilating SIC alone gave promising improvements in SIT in particular regions and seasons (e.g., over the Beaufort Sea from June to August) in Yang et al. (2015, 2016a).

Clearly assimilating SIT as well as SIC is a high priority. However, SIT observations from satellites contain large uncertainties because of large uncertainties in the input parameters needed to retrieve SIT and large differences in the instruments used to measure SIT from space (e.g., Kwok and Cunningham 2008; Tian-Kunze et al. 2014; Kaleschke et al. 2016; Tilling et al. 2016). Hence there are far fewer studies assimilating SIT data from satellite retrievals. Yang et al. (2014; 2016b) assimilated SIT observations derived from the Soil Moisture and Ocean Salinity (SMOS) satellite and showed the forecast SIT is improved in the first-year ice zone compared with sea ice draft observations from upwardlooking sonar moorings. Chen et al. (2017) assimilated SIT observations derived from SMOS and CryoSat-2 satellites in spring and found the forecast SIT is only improved in particular regions and times when compared to Operation IceBridge airborne observations of SIT, albeit the assimilation results match better with the SIT observations that were assimilated. Mu et al. (2017) assimilated SIT observations from SMOS and CryoSat-2 in the autumn-winter transition months and also demonstrated a better match with the assimilated SIT observations, and improvements are also identified over the Beaufort Sea compared with observations obtained from upward-looking sonar moorings ice mass balance buoys. Results from assimilating SIT to date are mixed and highly dependent on the particular model, assimilation algorithm, validating observation, and time periods examined.

Multiyear sea ice concentration (MYI) is the fraction of sea ice that survives at least one summer. Because multiyear sea ice is usually thicker than younger firstyear ice, MYI is positively correlated with SIT and might provide valuable information about SIT (Maslanik et al. 2007). MYI observations can be retrieved from satellite passive microwave observations (e.g., Belchansky et al. 2004) and satellite scatterometer backscatter fields (e.g., Kwok 2004; Nghiem et al. 2006). Nevertheless, MYI observations have never been assimilated into sea ice models. Our study represents the first effort to evaluate the feasibility and possible benefits of incorporating MYI data into a sea ice model.

We design perfect model observing system simulation experiments (OSSEs) to investigate a variety of questions. One goal is to investigate whether assimilating SIC observations could improve SIT estimates in our system, which is one of the few applying DA in a sea ice model with multiple thickness categories to resolve the ice thickness distribution. In such a model, SIC and SIT 
are aggregates of concentration and thickness across the ice thickness distribution. In addition, with OSSEs we directly assess the improvement to the model states from assimilating a variety of hypothetical observation types (e.g., SIC, SIT, and MYI). Improvements can be assessed in variables that are not well observed, like SIT and snow depths. We also test different DA algorithms and postprocessing methods. The findings from this study could help configure DA algorithms and postprocessing methods for real observation DA, estimate the importance of observed variables, and offer advice on designing observing networks.

Massonnet et al. (2015) were the first to apply a multivariate DA method [the ensemble Kalman filter (EnKF) in their case] in a sea ice model with multiple ice thickness categories. The EnKF allowed them to assimilate SIC observations from satellite retrievals to update unobserved variables such as the ice thickness distribution, as well as SIC. They found the ice thickness distribution updates were substantial. The results of the DA were used to initialize a retrospective forecast that showed improved predictive skill for total Arctic sea ice extent compared to a forecast initialized without DA. However, they did not explore the impact of their assimilation on SIT because of the previously mentioned shortcomings of SIT observations.

The sea ice model, DA framework, design of OSSEs, and indices used to evaluate model results are presented in section 2. We evaluate and discuss the results of the OSSEs in section 3 . We close with conclusions in section 4.

\section{Data and methodology}

\section{a. The DART/CICE sea ice data assimilation system}

The Los Alamos Sea Ice Model (CICE) is the sea ice component of the Community Earth System Model (CESM). Version 5 of this sea ice model (CICE5), used in this study, simulates ice and snow growth as a result of thermodynamic and dynamic processes with a subgridscale ice thickness distribution (Hunke et al. 2015). The ice thickness distribution is represented by partitioning the ice pack into multiple thickness categories. By default, there are five categories with the lower bounds of $0,0.64,1.39,2.47$, and $4.57 \mathrm{~m}$. Each thickness category has multiple vertical layers to resolve the sea ice temperature and salinity variations. The sea ice is coupled to a slab ocean with annually periodic, prescribed ocean heat fluxes, and sea ice and slab ocean are forced at the surface with atmospheric fields from the Community Atmosphere Model version 4 (CAM4)/Data Assimilation Research Testbed (DART) ensemble reanalysis (Raeder et al. 2012) for years 2001-03. These years are practical because they are near the middle of the satellite period, and approximate the average conditions since SIC observations have become available.

DART is community software that provides ensemblebased DA techniques to modelers and observationalists (Anderson et al. 2009). Previously, it had been linked with three of the physical components of the CESM [atmosphere (Raeder et al. 2012), ocean (Danabasoglu et al. 2012), and land (Zhang et al. 2014)], and had been demonstrated to effectively assimilate various observation types. This study describes the linking of the "Manhattan" release of DART with CICE5 to make a sea ice DA system capable of assimilating multiscale (i.e., observations with different spatial resolutions) and multivariate (i.e., different observed quantities) observations and convenient to explore a variety of data assimilation options.

The software interface to link CICE5 (as part of version 2 of the CESM) and DART is distributed with DART and requires no additional modifications to the CICE5 in CESM. Each time data are assimilated, CICE5 stops and writes a restart file. The DA interface reads the sea ice restart variables (or a subset of them as selected by the user) and the observations to be assimilated. The DA interface places the sea ice variables into a "DART state vector." The EnKF computes covariances between the DART state vector and observations and updates the state as necessary. Then the DA interface postprocesses the state to enforce various properties, including updating variables that are not in the DART state vector, creating temperature and salinity profiles for newly added sea ice, and limiting the aggregate SIC within its physical boundary from $0 \%$ to $100 \%$. At the last step, DART rewrites the state to the restart. Finally, CICE5 resumes integration with the modified restart.

\section{b. The EnKF}

Data assimilation is an approach to combine model forecasts and observations with weights determined by their relative error (e.g., Kalnay 2002). A typical sequential data assimilation cycle is composed of a forecast step, where model states advance to the time when observations are available, and an analysis step, where the model forecast and the observation are merged to obtain analysis states based on their error statistics. The EnKF is a Monte Carlo approach to the Kalman filter (Evensen 1992) that estimates the background error covariance from the statistics of an ensemble of model forecasts (Evensen 1994). One variant of the EnKF, the ensemble adjustment Kalman filter (EAKF), is used in this study; documentation of the EAKF can be found in Anderson (2001). 

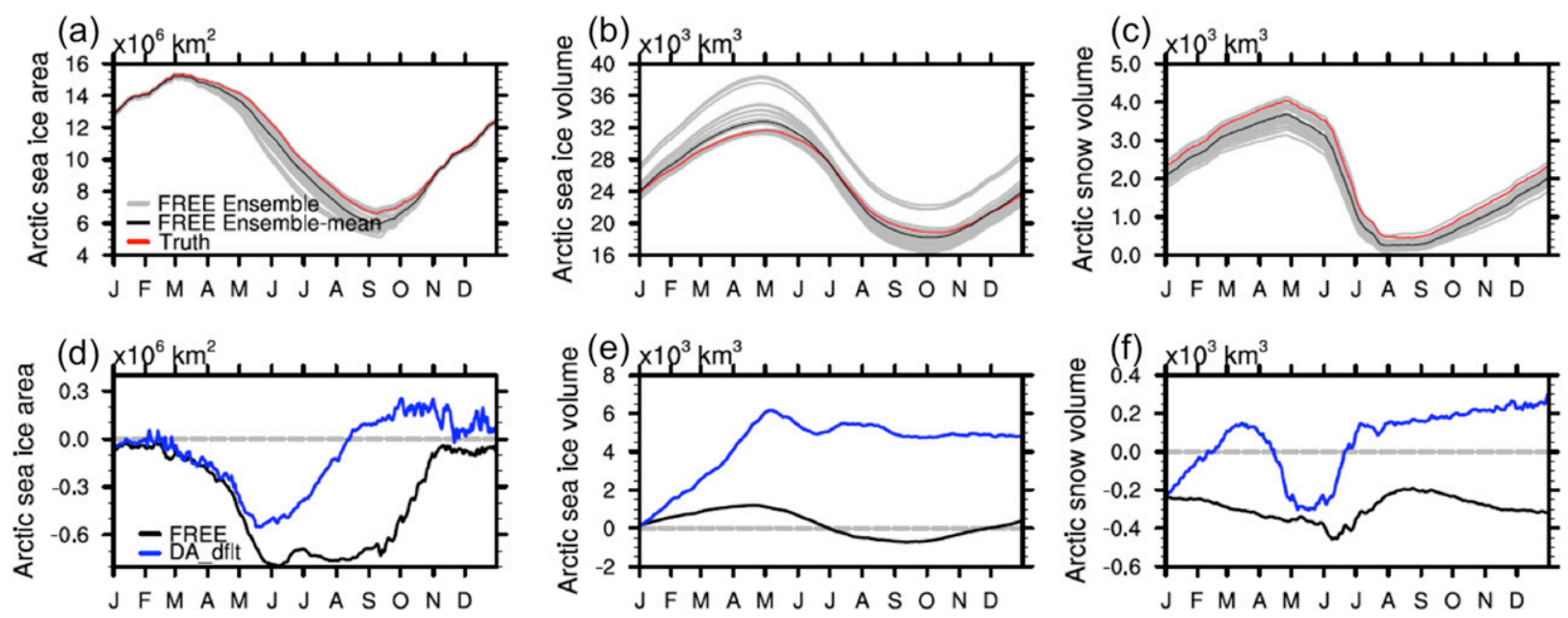

FIG. 1. Daily total Arctic (a) sea ice area, (b) sea ice volume, and (c) snow volume from a CICE5 free run. Each gray line represents one ensemble member, black line the ensemble mean, and red line the truth, which is just one member of the ensemble. Daily biases of the total Arctic (d) sea ice area, (e) sea ice volume, and (f) snow volume, with the black line representing the ensemble mean of FREE, blue line the ensemble mean of DA_dflt, and gray dashed line the zero reference line. The experiment time period is for the year 2001.

\section{c. Perfect model OSSES}

Given the shortage of SIT and snow-depth observations, and hence the difficulty of evaluating the results of real observation DA, our study applies perfect model OSSEs to investigate DA options and model processing methods and test the potential value of different observed quantities. Each of our integrations has 30 CICE5 ensemble members. Sampling error due to limited ensemble size is a challenge for all ensemble filters, but we confirmed that 30 members are sufficient to explore the important questions in this study. The CICE5 ensemble is created by forcing each member with atmospheric fields from a given ensemble member from a CAM4/DART ensemble reanalysis (Raeder et al. 2012). We enhance the CICE5 ensemble spread by using different albedo and ice strength parameters for each ensemble member. We perturb the dry snow grain radius (R_snw) to adjust albedo and the empirical ice strength parameter (Cf). R_snw and Cf are among the parameters that the model predictions are sensitive to (UrregoBlanco et al. 2016).

A CICE5 ensemble integration without DA, known as a free run (FREE), is produced as a reference case. One of the FREE ensemble members is chosen randomly as the simulated "truth" (Figs. 1a-c). We assume that only aggregate quantities could be observed, so the multicategory model variables from the truth are aggregated to compute the true SIC, MYI, and SIT. We use the convention of upper-case names for aggregated variables and lower-case names for category-based variables. We create synthetic observations from these aggregate variables by adding a draw from a normal distribution with zero mean and specified standard deviation to the true quantities. The standard deviations are $15 \%$ of the true value for SIC and MYI [an approximate combination of bias and precision of the satellite-based concentration data; e.g., Meier (2005)] and $0.1 \mathrm{~m}$ for SIT (an estimate in anticipation of high precision future data). The model variables that are updated and/or postprocessed are aicen, vicen, and vsnon, representing category-based sea ice concentration, sea ice volume, and snow volume, respectively.

Table 1 summarizes the OSSEs conducted with different configurations that can be grouped into two sets. The first set (DA_dflt, DA_aicen, and DA_inf_ loc) is produced to determine the best combination of DA algorithms and postprocessing methods for SIC-only assimilation. The second set (DA_SIC, DA_SIC_SIT, and DA_SIC_MYI) is produced to assess the impact of different observation types and is analyzed for years 2001-03.

The DA experiment with default options (DA_dflt) has greatly reduced bias in the aggregate SIC, but experiences temporal drift in the concentration of several of the ice categories that sum to a negligible drift in the aggregate. The additional two experiments test modifications to eliminate this drift, while maintaining the reduced bias in the aggregate SIC. The drift in DA_dflt occurs within a few months, so experiments in the first set were analyzed for just one year (i.e., 2001).

Experiment DA_dflt assimilates SIC observations with aicen, vicen, and vsnon updated directly by the EnKF with a localization method (Anderson 2007a) that 
TABLE 1. List of CICE5 experiments with different configurations.

\begin{tabular}{|c|c|c|c|c|c|c|}
\hline Expt & $\begin{array}{l}\text { Assimilated } \\
\text { observations }\end{array}$ & $\begin{array}{l}\text { State } \\
\text { vector }\end{array}$ & $\begin{array}{l}\text { Postprocessed } \\
\text { states }\end{array}$ & Inflation & $\begin{array}{c}\text { Localization half-width } \\
{[\mathrm{rad}(\mathrm{km})]}\end{array}$ & $\begin{array}{l}\text { Expt time } \\
\text { period }\end{array}$ \\
\hline FREE & - & - & - & - & - & $2001-03$ \\
\hline DA_dflt & SIC & $\begin{array}{l}\text { aicen, vicen, } \\
\text { and vsnon }\end{array}$ & - & No & $0.05(320)$ & 2001 \\
\hline DA_aicen & SIC & aicen & vicen and vsnon & No & $0.05(320)$ & 2001 \\
\hline DA_inf_loc (DA_SIC) & SIC & aicen & vicen and vsnon & Yes & $0.01(64)$ & $2001-03$ \\
\hline DA_SIC_SIT & SIC and SIT & aicen & vicen and vsnon & Yes & $0.01(64)$ & $2001-03$ \\
\hline DA_SIC_MYI & SIC and MYI & aicen & vicen and vsnon & Yes & $0.01(64)$ & $2001-03$ \\
\hline DA_SIT_LOC0.01 & SIT & aicen & vicen and vsnon & Yes & $0.01(64)$ & 2001 \\
\hline DA_SIT_LOC0.05 & SIT & aicen & vicen and vsnon & Yes & $0.05(320)$ & 2001 \\
\hline DA_SIT_LOC0.1 & SIT & aicen & vicen and vsnon & Yes & $0.1(640)$ & 2001 \\
\hline
\end{tabular}

uses a Gaspari-Cohn-function (Gaspari and Cohn 1999) half-width of $0.05 \mathrm{rad}$ (about $320 \mathrm{~km}$ ). The influence of an observation is limited within a circle with a radius of 2 half-widths. One unique feature of EnKF is that unobserved model states can be directly updated in the analysis step based on their correlations with the observed variable, which facilitates multivariate data assimilation schemes (Evensen 2003). Thus, the ice concentration, as well as other sea ice states, of individual categories can be updated when the observations of aggregate quantities are assimilated. In experiment DA_dflt, aicen, vicen, and vsnon are updated in the analysis step based on their correlation with SIC.

Certain treatments applied to the updated state are necessary when special conditions occur. First of all, SIC (the sum of aicen over five categories) must be bounded between $0 \%$ and $100 \%$. If a negative SIC should ever arise, all aicen are subsequently set to zero, Likewise, aicen are scaled if needed so that SIC never exceeds $100 \%$. If SIC is within its bounds but several individual categories become negative, aicen of those categories are set to 0 and aicen of other categories are reduced proportionally to compensate for the negative amount. If all ensemble members are ice-free while the observation has ice, no adjustment is made.

Experiment DA_aicen is identical to DA_dflt except that the EnKF only updates aicen directly, while vicen and vsnon are only modified by postprocessing as follows:

$$
\begin{aligned}
\text { vicen }^{+} & =\text {aicen }^{+} \times \text {hicen }^{-} \text {and } \\
\text { vsnon }^{+} & =\text {aicen }^{+} \times \text {hsnon }^{-},
\end{aligned}
$$

where the superscript plus symbol indicates posterior and minus symbol indicates prior, and hicen and hsnon are category-based sea ice thickness and snow thickness, respectively.

Experiment DA_inf_loc uses the same postprocessing method as DA_aicen and an adaptive inflation algorithm (Anderson 2007b) applied to the prior states.
State inflation is usually employed to modify the state variance to account for unconsidered errors and to avoid filter divergence (e.g., Anderson and Anderson 1999; Whitaker and Hamill 2012). An initial inflation value of 1.0, a standard deviation of 0.6 , and an inflation damping of 0.9 are specified in DART. The adaptive inflation aims to maintain the model ensemble spread so the ensemble members do not converge after several DA cycles. The localization half-width is decreased to a much smaller value, $0.01 \mathrm{rad}$ (about $64 \mathrm{~km}$ ), to restrict the influence of each observation to a few neighboring grid cells. We also conducted an experiment applying inflation only, but it has little influence on the ice thickness distribution, hence is not discussed explicitly here. Experiment DA_inf_loc gives the best results, so its DA algorithms and postprocessing are used for set 2.

Experiment DA_SIC is the same as DA_inf_loc; the name is changed for simplicity when comparing with the remaining experiments and indicates that only SIC is assimilated. Experiment DA_SIC_SIT assimilates SIC and SIT observations with other options the same as DA_SIC. Experiment DA_SIC_MYI assimilates SIC and MYI observations jointly with other options the same as DA_SIC.

All experiments are initialized on 1 January 2001. A spinup case is run for 40 years using periodic atmospheric forcing of year 2000 so the sea ice states reach equilibrium. Then a case with 30 CICE members, each member using a distinct atmospheric forcing and parameter set and initialization from the same equilibrated sea ice state, is run for the year 2001, which produces an ensemble of initial conditions for the experiments listed in Table 1. For the assimilation experiments, observations are assimilated at a daily interval.

\section{d. Metrics used to evaluate model results}

Bias is defined as the 30-member ensemble mean of the experiments minus the truth. Biases of the total Arctic sea ice area, sea ice volume, and snow volume are 
calculated every day. The total Arctic sea ice area is the area actually covered by sea ice in the Northern Hemisphere, while the aforementioned Arctic sea ice extent is the total area in the Northern Hemisphere where sea ice concentration exceeds $15 \%$. The two measurements give slightly different information and we use both.

The mean absolute bias (MAB) of a variable (e.g., total Arctic sea ice area) is calculated as follows:

$$
\mathrm{MAB}=\frac{\sum_{i=1}^{N}\left|x_{i}^{m}-x_{i}^{t}\right|}{N},
$$

where $i$ is the index in time, $N$ is the sample size (i.e., the number of days calculated), $x_{i}^{m}$ is the ensemble mean, and $x_{i}^{t}$ is the true value of the variable.

Another commonly used statistical measure of model performance is the root-mean-square error (RMSE), defined as follows:

$$
\mathrm{RMSE}=\sqrt{\frac{\sum_{i=1}^{N}\left(x_{i}^{m}-x_{i}^{t}\right)^{2}}{N}},
$$

where $i$ is also the index in time, and $x$ can refer to total Arctic ice area, ice volume, and snow volume or SIC, SIT, and snow depth (SNO) at grid points. We use both RMSE and MAB to evaluate model performance.

Evaluating the total Arctic sea ice area or volume is useful but sometimes can be misleading. Smaller MAB or RMSE may result when positive and negative errors at the regional scale compensate for each other, so we also calculate the RMSE of the sea ice states at each grid point and evaluate the RMSE spatially.

The integrated ice-edge error (IIEE) is another index used to evaluate sea ice cover in this study. The IIEE is the sum of the area of grid boxes where the experiment and the truth disagree on whether sea ice is present or not. A SIC threshold of $15 \%$ is used to determine if a grid cell has sea ice present. IIEE can be decomposed into an absolute extent error (AEE) and a misplacement error (ME). AEE is the commonly used sea ice extent error. ME is the residual error (IIEE minus AEE) that reflects excessive sea ice in one place and insufficient sea ice in another place, which is found to dominate IIEE in model forecasts (Goessling et al. 2016).

\section{Results and discussion}

\section{a. Optimization of SIC data assimilation}

In the DA_dflt experiment, the only assimilated observations are the aggregate SIC, while the prognostic variables that are updated are category-based ice concentration, ice volume, and snow volume (aicen, vicen, and vsnon). Figure $1 \mathrm{~d}$ shows that the total Arctic sea ice area is significantly improved after assimilating SIC observations, but Fig. 1e indicates that the total Arctic sea ice volume experiences large degradation. The total Arctic snow volume is slightly improved, with negative biases becoming more positive biases (Fig. 1f). We show in Fig. 2 spatial maps of monthly mean biases in the spring (April-May) for SIC, SIT, and aggregate SNO to illustrate where improvement and degradation occur at the local scale. These maps show that SIC is indeed improved along the ice edge (Fig. 2a). However, the slight improvement in the total Arctic snow volume as shown in Fig. 1f is only because the positive biases in SNO in the central Arctic and along the Fram Strait compensate for the negative biases in SNO elsewhere (Fig. 2c). Clearly, SIT is degraded almost everywhere (Fig. 2b). Previous studies also suggest that SIT errors could grow despite the fact that SIC is improved (e.g., Kimmritz et al. 2018).

The disappointing results of DA_dflt may be explained by three issues. Spurious and fake correlations might exist between SIC and aicen or vicen because of sampling errors. Further, the EnKF assumes an approximately Gaussian distribution for the ensemble in the state variables that are updated. Our postprocessing then restricts aicen (for each category and for the sum) to the range from $0 \%$ to $100 \%$ and vicen to be nonnegative. The ratio vicen/ aicen is non-Gaussian and generally has an ensemble mean shifted higher than the ratio of the ensemble means of vicen and aicen and a long tail toward higher thickness. Moreover, the ice thickness distribution method in CICE5 requires the diagnosed category thickness (vicen/aicen) to lie within category thickness boundaries. The model normally only has to shift ice from adjacent categories when the ice grows or melts. Figure 3 demonstrates that DA_dflt moves more area into the fourth and fifth categories (the highest thickness categories), which can partly explain why DA_dflt has large positive biases in ice volume. Experiment FREE has a large negative bias in snow volume year-round (Fig. 1f). Because snow is usually thinner over younger and thinner sea ice (e.g., Kurtz and Farrell 2011), decreased ice area in thin categories and increased ice area in thick categories causes increased average snow depth. This increase of snow depth compensates for the negative bias found in FREE, which is consistent with Fig. 2c.

Experiment DA_aicen is designed to maintain the ice thickness and snow depth of each category and let the ice area be the only variable directly altered by observations. In this case, vicen and vsnon are only modified by the postprocessing as given in Eqs. (1) and (2). This 

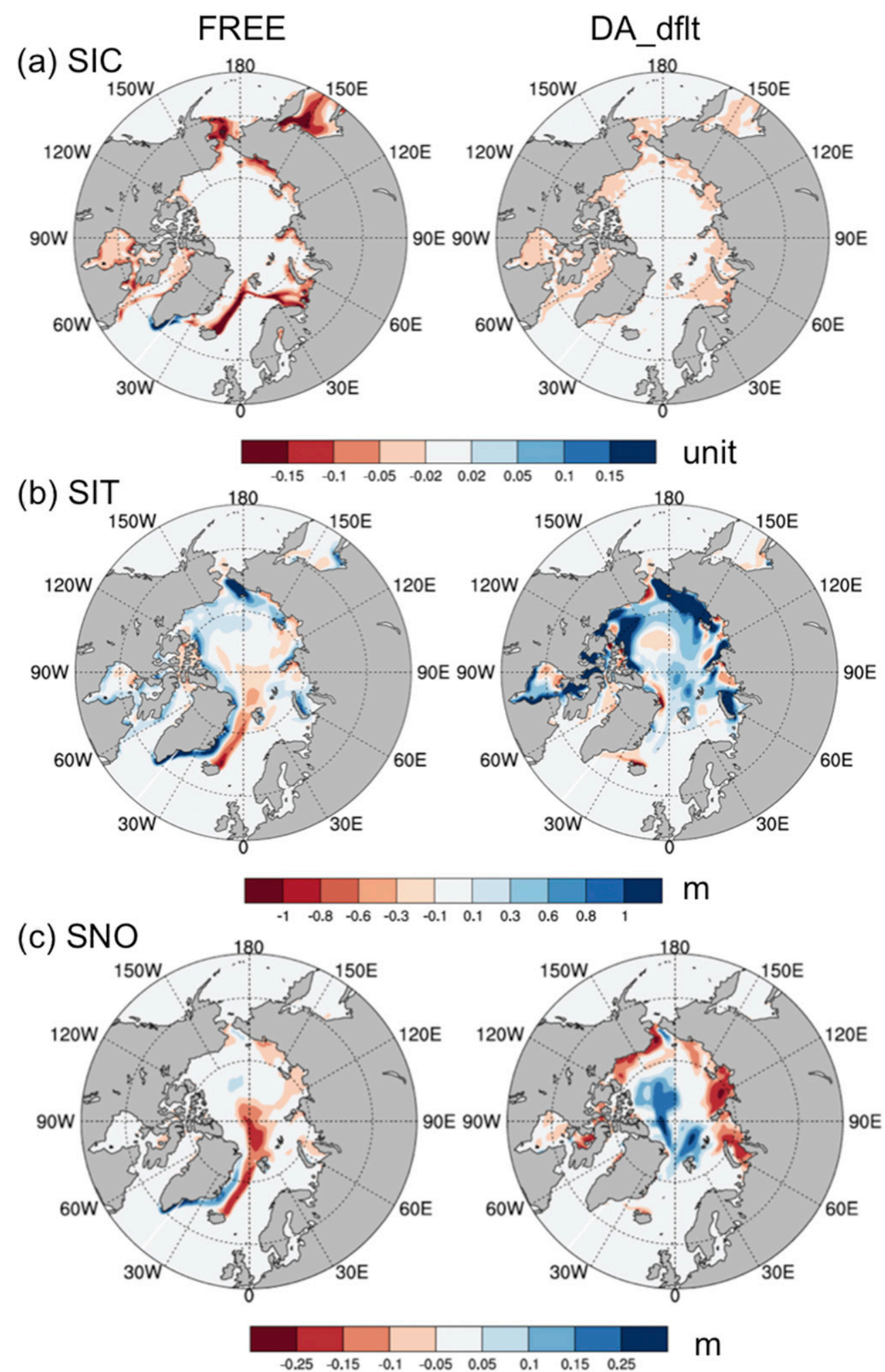

FIG. 2. The 2001 spring (April-May) mean biases of (a) SIC, (b) SIT, and (c) SNO, for the experiments (left) FREE and (right) DA_dflt. 


\section{Arctic sea ice area $\left(\times 10^{6} \mathrm{~km}^{2}\right)$}
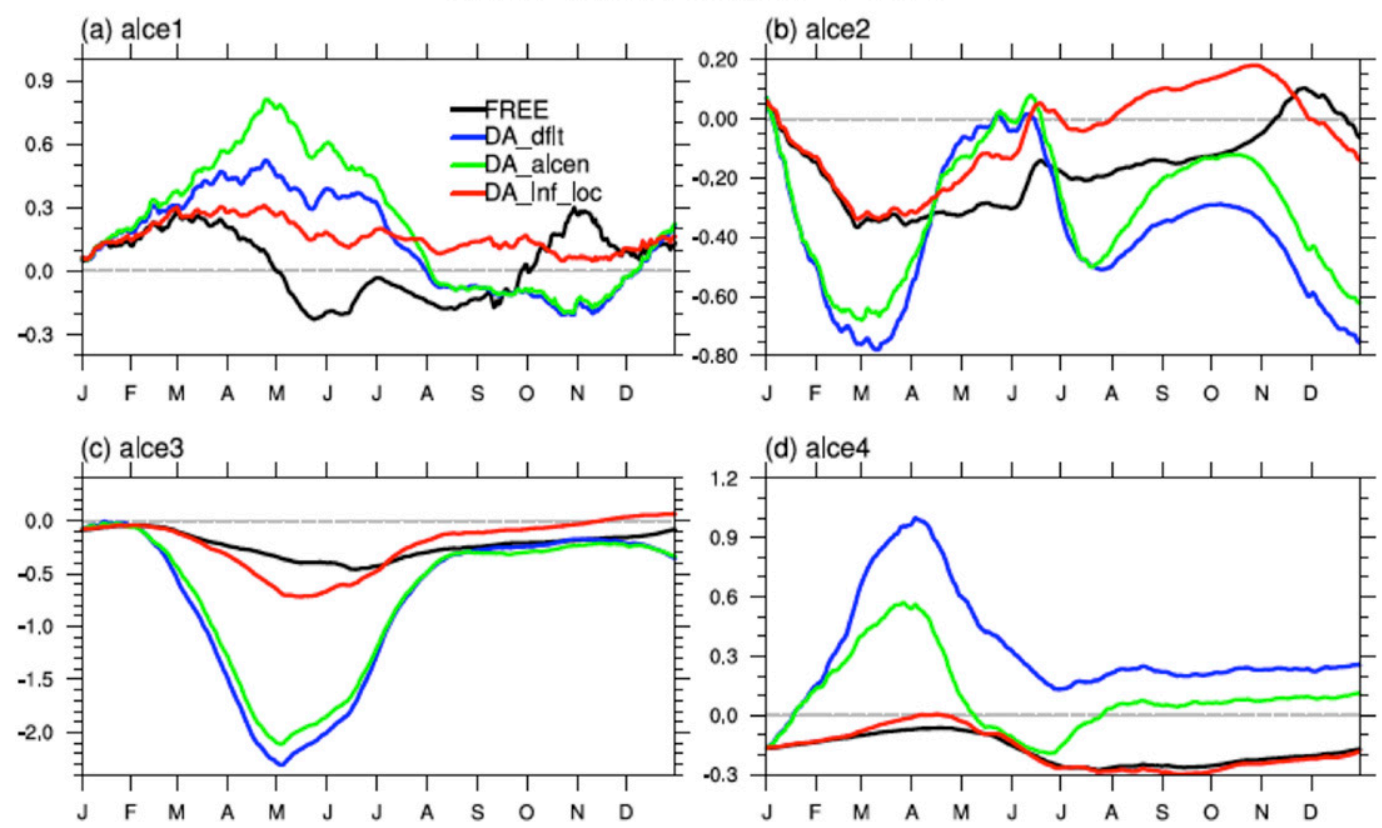

(e) alce5

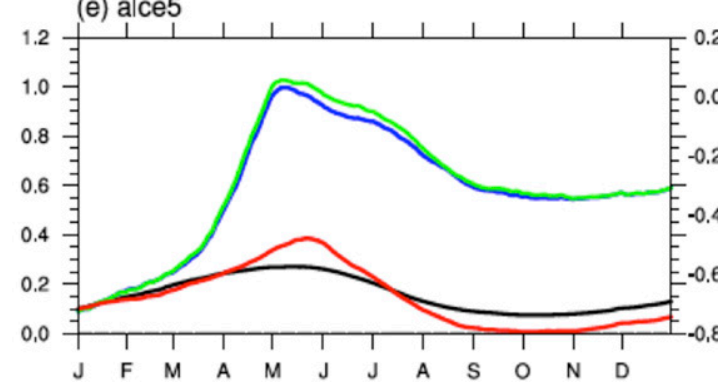

(f) $\mathrm{SIC}$

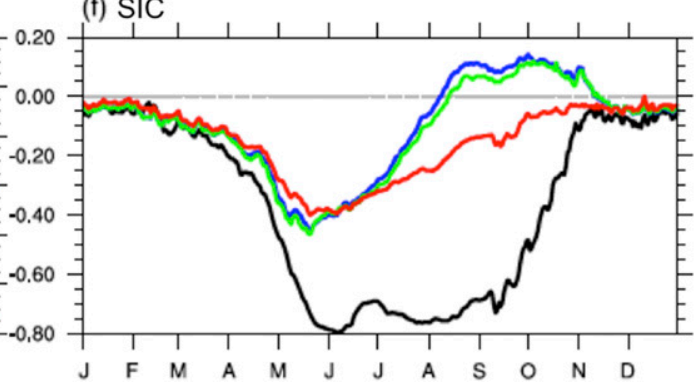

FIG. 3. Daily biases of the total Arctic sea ice area in 2001 of (a)-(e) individual categories and (f) the aggregate, for FREE (black), DA_dflt (blue), DA_aicen (green), and DA_inf_loc (red). Gray line in each plot represents the zero reference line.

treatment does not influence the total Arctic sea ice area very much, but improves the distribution of total Arctic sea ice area among the five categories as shown in Fig. 3. The temporal RMSE of total Arctic sea ice volume is reduced from 4.609 to $3.607 \times 10^{3} \mathrm{~km}^{3}$, and the MAB of the total volume is reduced from 4.347 to $3.410 \times 10^{3} \mathrm{~km}^{3}$ (Table 2). Figure 4a confirms that, although SIC is improved in DA_dflt, the amount of ice in individual

TABLE 2. The IIEE, RMSE, and MAB of the Arctic ice area, ice volume, and snow volume from four experiments: FREE, DA_dflt,

DA_aicen, and DA_inf_loc. Boldface numbers in the columns of DA experiments indicate DA has a smaller index than FREE.

\begin{tabular}{|c|c|c|c|c|c|}
\hline & & \multicolumn{4}{|c|}{ Experiments } \\
\hline \multicolumn{2}{|c|}{ Indices } & FREE & DA_dflt & DA_aicen & DA_inf_loc \\
\hline \multirow[t]{3}{*}{$\operatorname{IIEE}\left(10^{6} \mathrm{~km}^{2}\right)$} & Total IIEE & 1.049 & 0.847 & 0.849 & 0.768 \\
\hline & AEE & 0.559 & 0.469 & 0.463 & 0.516 \\
\hline & $\mathrm{ME}$ & 0.491 & 0.378 & 0.386 & 0.252 \\
\hline \multirow[t]{3}{*}{ RMSE } & Ice area $\left(10^{6} \mathrm{~km}^{2}\right)$ & 0.481 & 0.186 & 0.192 & 0.193 \\
\hline & Ice volume $\left(10^{3} \mathrm{~km}^{3}\right)$ & 0.673 & 4.622 & 3.620 & 0.799 \\
\hline & Snow volume $\left(10^{3} \mathrm{~km}^{3}\right)$ & 0.300 & 0.168 & 0.262 & 0.294 \\
\hline \multirow[t]{3}{*}{ MAB } & Ice area $\left(10^{6} \mathrm{~km}^{2}\right)$ & 0.380 & 0.143 & 0.143 & 0.149 \\
\hline & Ice volume $\left(10^{3} \mathrm{~km}^{3}\right)$ & 0.581 & 4.363 & 3.423 & 0.692 \\
\hline & Snow volume $\left(10^{3} \mathrm{~km}^{3}\right)$ & 0.293 & 0.155 & 0.252 & 0.284 \\
\hline
\end{tabular}




\section{DA_dflt-FREE DA_aicen-FREE DA_inf_loc-FREE}

(a) aice4

(b) SIC
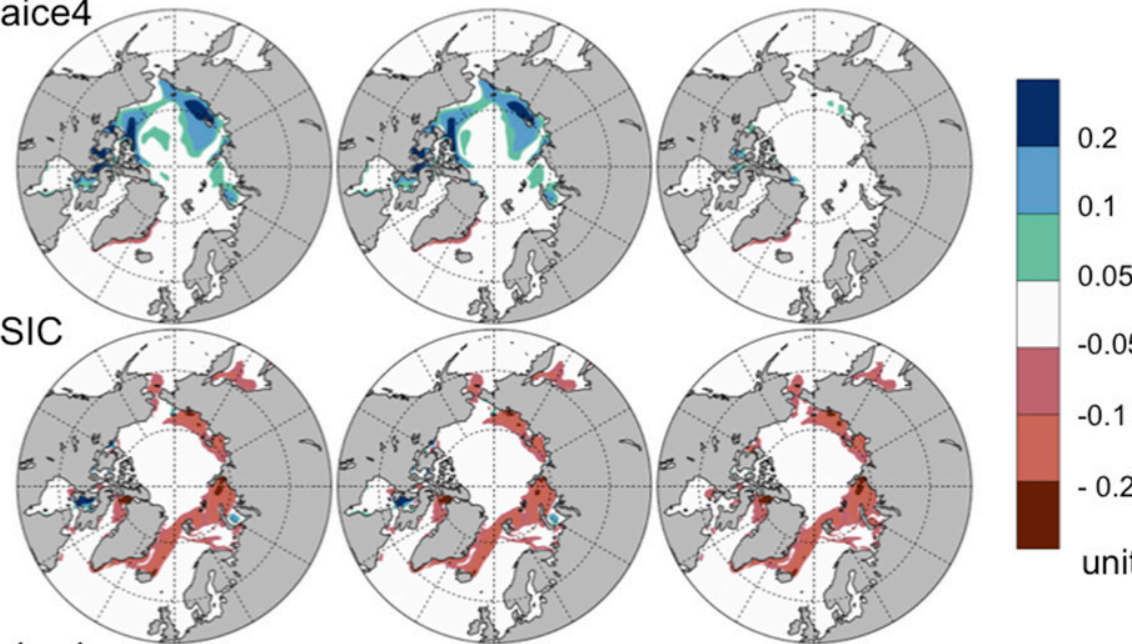

(c) vice4
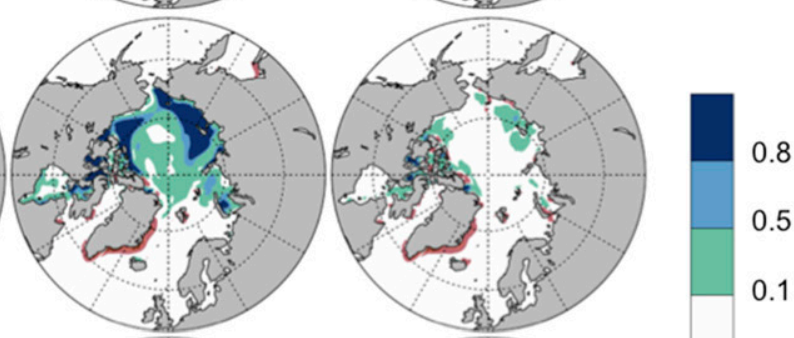

(d) SIT
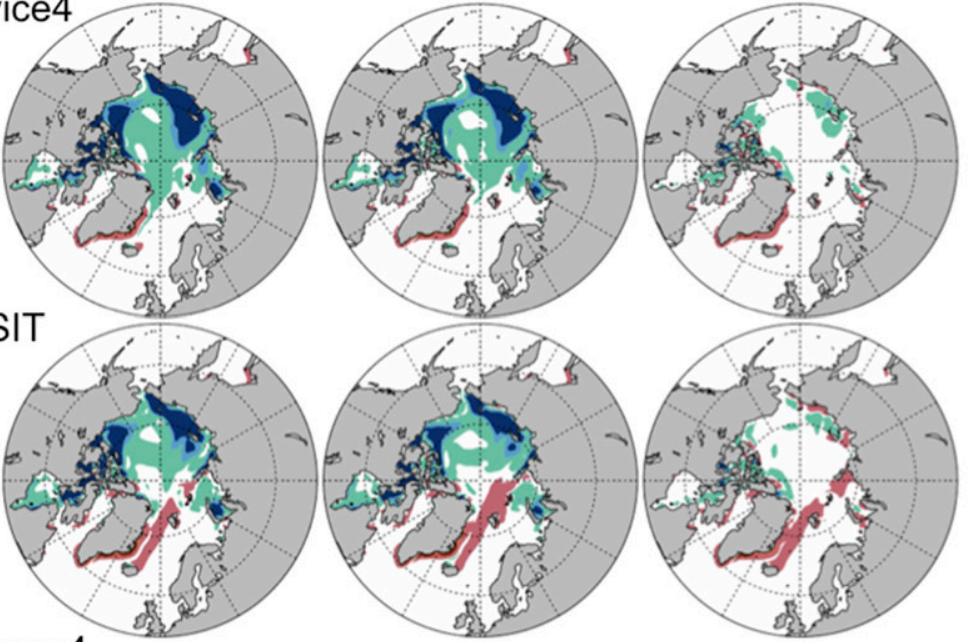

-0.1
-0.5
-0.8
$\mathrm{~m}$

(e) vsno4
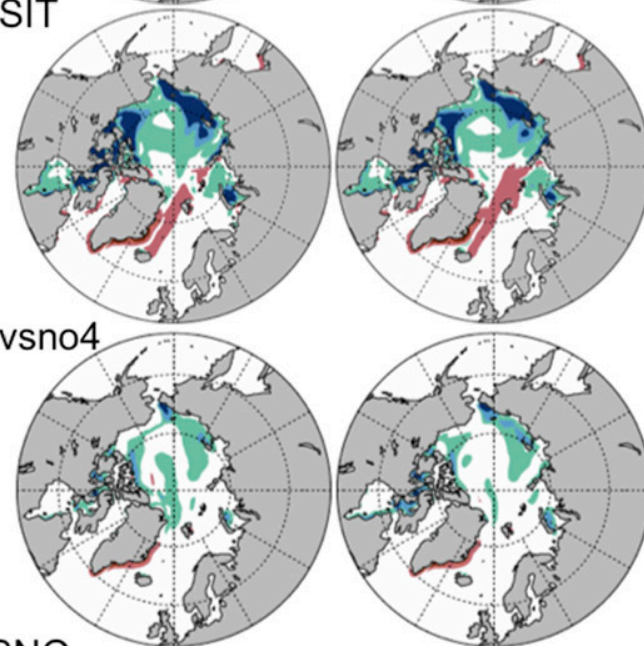

(f) $\mathrm{SNO}$
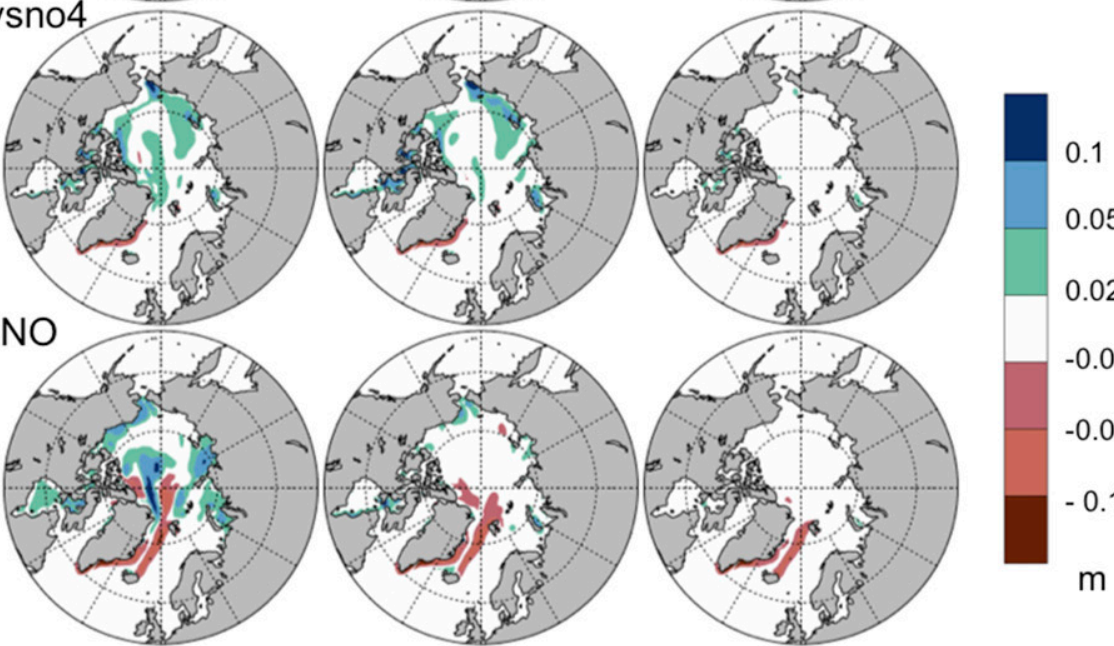

0.1

0.05

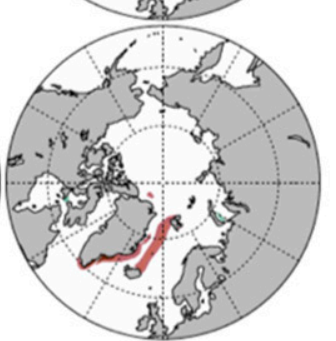

0.02

$-0.02$

$-0.05$

$-0.1$

m

FIG. 4. RMSE of (a) aice4, (b) SIC, (c) vice4, (d) SIT, (e) vsno4, and (f) SNO for (left)(right) DA_dflt minus FREE, DA_aicen minus FREE, and DA_inf_loc minus FREE. Negative values indicate the DA cases outperform FREE, while positive values indicate DA degrades result. Daily model output in 2001 is used to calculate RMSE. 
(a) $\operatorname{corr}($ aice3, SIC)

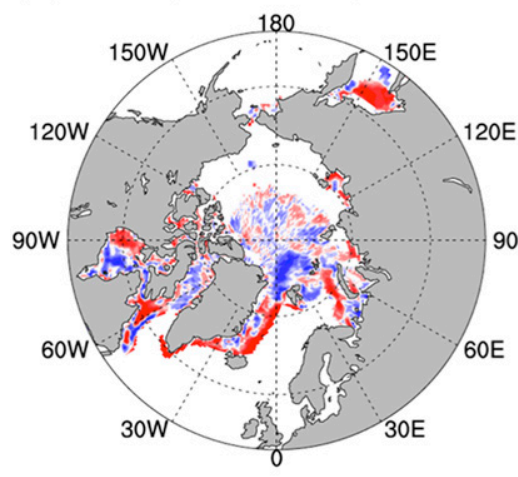

(b) corr (aice3, SIT)

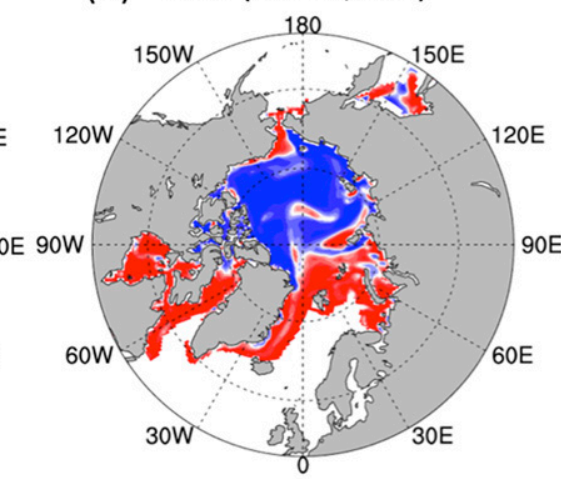

(c) corr (aice3, MYI)

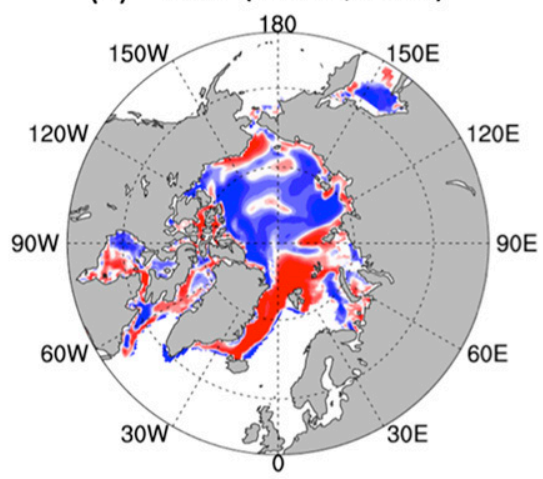

$-0.8$

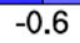

$-0.4$

$-0.2$

$-0.1$

0.1

0.2

0.4

0.6

0.8

FIG. 5. Local correlations between SIC of the third thickness category and different observation types: (a) the aggregate SIC, (b) the aggregate SIT, and (c) the aggregate MYI. At each point, we calculate the correlation of the observation and aice 3 across the 30 ensemble members for 1 Mar 2001, an arbitrary date (see text).

categories (aicen in the fourth category is shown for illustration) is degraded. Experiment DA_aicen improves over DA_dflt slightly: SIC is less biased in the central Arctic and along the Fram Strait, and SNO errors are removed along the coast and in the central Arctic. However, the results of DA_aicen are disappointing, as there still are larger errors in SIT than FREE.

We apply an adaptive inflation and a localization scheme to reduce sampling errors in the experiment DA_inf_loc. Experiment DA_inf_loc generally reduces the ice area biases in every category (Figs. 3a-e). The RMSE of SIC in individual categories is also reduced (the fourth category is shown in the left column of Fig. $4 c$ as an example). The MAB and RMSE of the total Arctic ice area are roughly half of those of FREE, although they are not always smaller than DA_dflt and DA_aicen. Experiment DA_inf_loc also produces the smallest IIEE with a notable reduction in ME (Table 1). The large bias in the total Arctic sea ice volume produced by DA_dflt and DA_aicen is reduced by an order of magnitude. Comparing Fig. $4 \mathrm{c}$ with Figs. 4a, $\mathrm{b}$ indicates that DA_inf_loc improves the spatial pattern of SIC over DA_dflt and DA_aicen, but has very limited influence on SIT and SNO as compared to FREE.

Results of the above experiments suggest that we should be cautious when updating the unobserved model state variables. Given a limited ensemble size and nonlinear relationships between the model variables and the observation, it might be problematic to increment unobserved model variables directly through the EnKF. Kimmritz et al. (2018) also experienced bias growth in SIT in their SIC DA experiments because of unrealistic updates on thick sea ice categories. They chose to preserve the mean ice thickness of each category to mitigate such a drift. No localization was applied in their study. Massonnet et al. (2015) performed a localization radius of $800 \mathrm{~km}$ to SIC DA, which was based on the spatial scale for decorrelation of SIT found by Blanchard-Wrigglesworth and Bitz (2014). However, better performance with a smaller localization halfwidth in our study indicates that the correlation length scale of SIC may be quite small. We discuss more about the different correlation length scales between SIC and SIT later, in section 3c. In summary, to maintain/improve the ice thickness distribution, we allow an observation to influence only a few neighboring grid cells.

\section{b. Assimilation of multivariate observations}

Other rarely assimilated observations of sea ice include SIT and MYI. As mentioned in the introduction, MYI data are underutilized and have not been assimilated into sea ice models. The joint SIC and SIT DA has been done before with real data (e.g., Yang et al. 2015, 2016a). However, given the large uncertainty and limited availability of real SIT data, our study has value in quantifying the potential of higher-quality SIT and seasonally complete observations as motivation for producing better observations.

The relative importance of these observation types to a large extent depends on whether they have a good correlation with the analyzed state variables, which are just aicen in this second set of experiments. Figure 5 displays correlations between ice concentration of the third category, aice3, and the observations (SIC, SIT, and MYI) for an arbitrary day chosen to show that correlations are generally strong between aicen and SIT, moderate to strong between MYI and SIT, and mostly weak between aicen and SIC. In the particular date chosen, the correlation between aice 3 and SIC is largest 

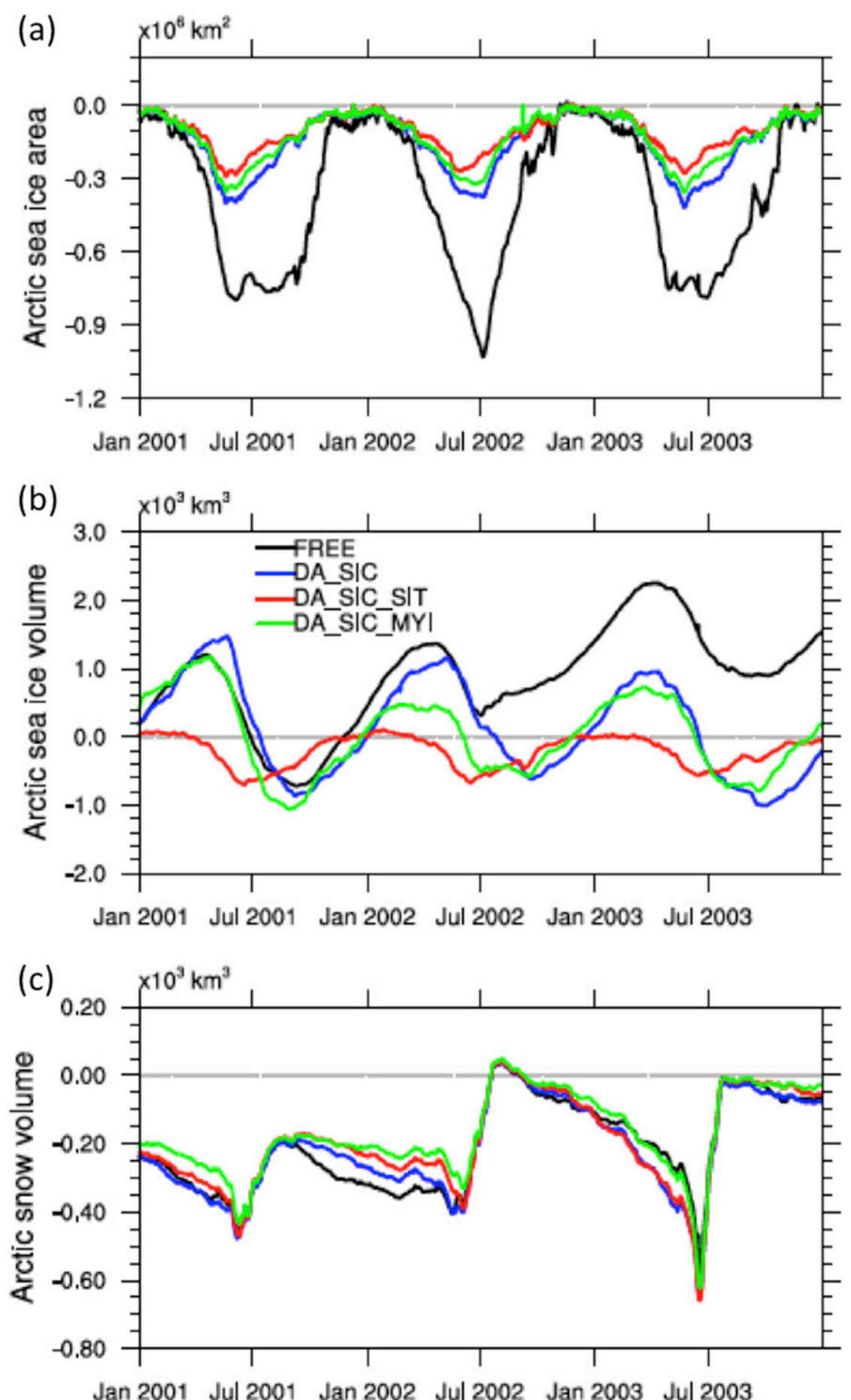

FIG. 6. Daily biases of the Arctic total (a) sea ice area, (b) sea ice volume, and (c) snow volume from four experiments: FREE (black line), DA_SIC (blue line), DA_SIC_SIT (red line), and DA_SIC_MYI (green line). Gray lines are the zero reference line. The experiment time period is from 2001 to 2003 . 


\section{FREE DA SIC DA SIC SIT DA SIC MYI}

(a) RMSE of SIC

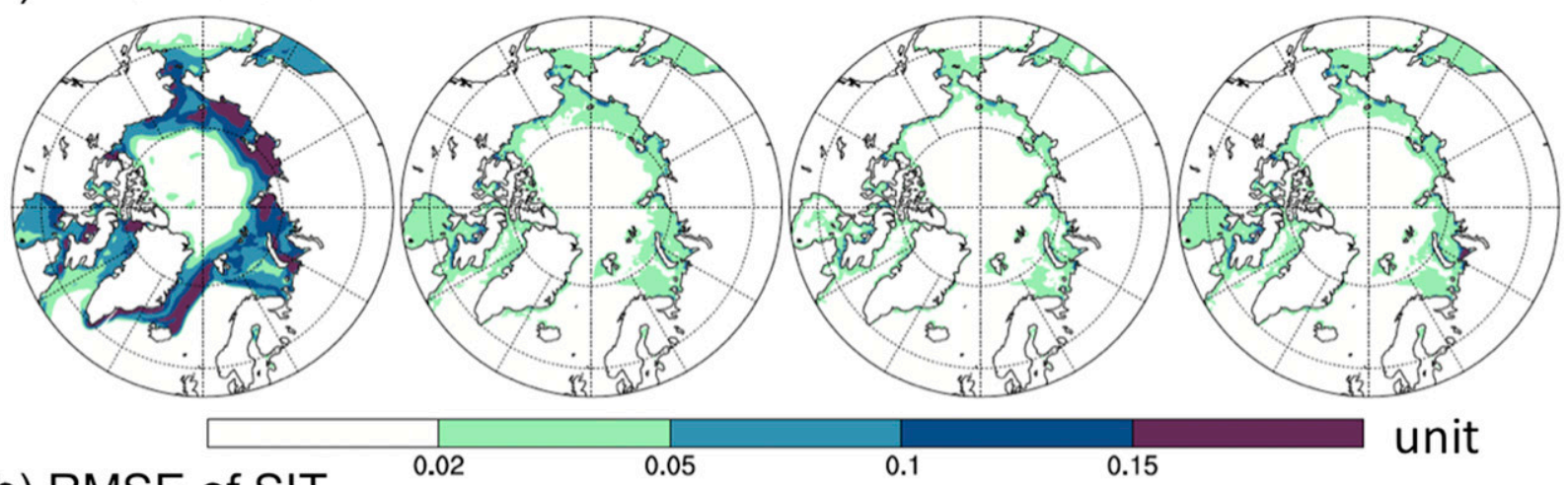

(b) RMSE of SIT

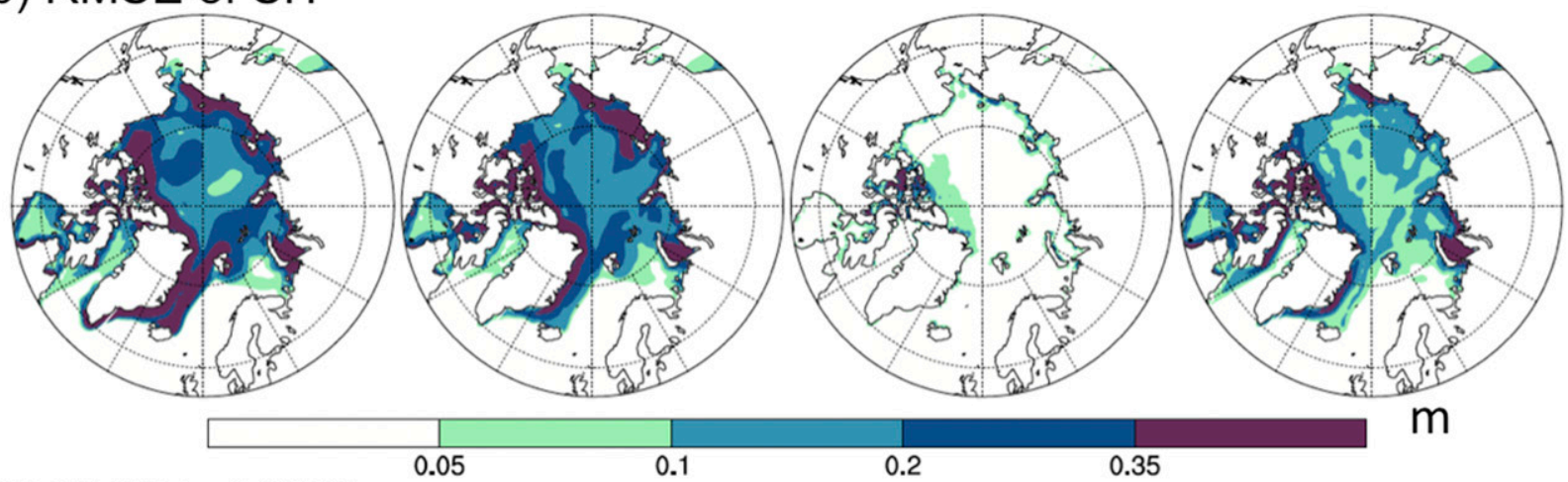

(C) RMSE of SNO

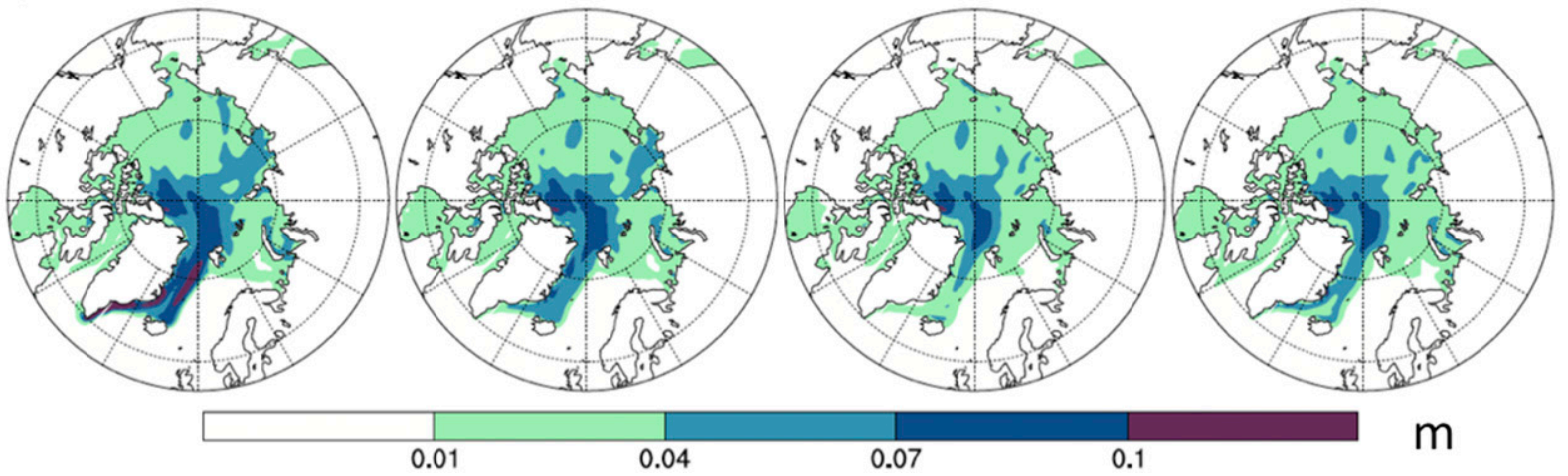

FIG. 7. RMSE of (a) SIC, (b) SIT, and (c) SNO from four experiments: (left)-(right) FREE, DA_SIC, DA_SIC_SIT, and DA_SIC_MYI. Daily model output from 2001 to 2003 is used to calculate RMSE.

primarily along the ice edge and is very small and noisy in the central Arctic, where SIC hardly has any ensemble spread (Fig. 5a). SIT has a much larger correlation with aice3 for the whole Arctic (Fig. 5b). The correlation between MYI and aice3 is in between (Fig. 5c). The specific patterns are seasonally variable.

As shown in Figs. 6a and 7a, the additional assimilation of SIT (DA_SIC_SIT) and MYI (DA_SIC_MYI) slightly improves the total Arctic sea ice area and SIC spatially over DA_SIC. For the total Arctic sea ice volume, DA_SIC starts to outperform FREE after one year, DA_SIC_SIT always performs the best throughout the experiment period, and DA_SIC_MYI is intermediate (Fig. 6b). Figure 7b further demonstrates that DA_SIC has the least influence on SIT, with improvements limited to the Beaufort Sea, Fram Strait, and the Greenland Sea. DA_SIC_SIT performs the best, with almost all the errors removed, and DA_SIC_MYI works reasonably well too, with large improvements over the whole Arctic. 
TABLE 3. The IIEE, RMSE, and MAB of ice area, ice volume, and snow volume from FREE and three DA experiments: DA_SIC, DA_ SIC_SIT, and DA_SIC_AGE. Each index is given in annual mean and spring (April-May) mean. Each boldface number indicates DA has a smaller error index, and each italic number indicates the case has the smallest error index among the four experiments. Each percentage in parentheses indicates the decrease or increase of error index compared against FREE.

\begin{tabular}{|c|c|c|c|c|c|c|}
\hline & & & \multicolumn{4}{|c|}{ Experiments } \\
\hline \multicolumn{3}{|c|}{ Indices } & FREE & DA_SIC (DA_inf_loc) & DA_SIC_SIT & DA_SIC_MYI \\
\hline \multirow[t]{6}{*}{$\operatorname{IIEE}\left(10^{6} \mathrm{~km}^{2}\right)$} & \multirow[t]{2}{*}{ Total IIEE } & Annual & 1.143 & $0.829(-28 \%)$ & $0.820(-28 \%)$ & $0.829(-28 \%)$ \\
\hline & & Spring & 0.932 & $0.732(-22 \%)$ & $0.723(-22 \%)$ & $\mathbf{0 . 7 3 0}(-22 \%)$ \\
\hline & \multirow[t]{2}{*}{ AEE } & Annual & 0.599 & $0.563(-6 \%)$ & $0.560(-6 \%)$ & $0.557(-7 \%)$ \\
\hline & & Spring & 0.520 & $0.441(-15 \%)$ & $0.432(-17 \%)$ & $0.434(-17 \%)$ \\
\hline & \multirow[t]{2}{*}{ ME } & Annual & 0.544 & $0.265(-51 \%)$ & $0.260(-52 \%)$ & $0.272(-50 \%)$ \\
\hline & & Spring & 0.412 & $0.291(-29 \%)$ & $0.291(-29 \%)$ & $0.297(-28 \%)$ \\
\hline \multirow[t]{6}{*}{ RMSE } & \multirow[t]{2}{*}{ Ice area $\left(10^{6} \mathrm{~km}^{2}\right)$} & Annual & 0.470 & $0.192(-59 \%)$ & $0.134(-71 \%)$ & $0.165(-65 \%)$ \\
\hline & & Spring & 0.577 & $0.281(-51 \%)$ & $0.202(-65 \%)$ & $0.250(-57 \%)$ \\
\hline & \multirow[t]{2}{*}{ Ice volume $\left(10^{3} \mathrm{~km}^{3}\right)$} & Annual & 1.128 & $0.713(-37 \%)$ & $0.315(-72 \%)$ & $0.582(-48 \%)$ \\
\hline & & Spring & 1.557 & $1.090(-30 \%)$ & $0.284(-82 \%)$ & $0.710(-54 \%)$ \\
\hline & \multirow[t]{2}{*}{ Snow volume $\left(10^{3} \mathrm{~km}^{3}\right)$} & Annual & 0.248 & $0.254(2 \%)$ & $0.237(-5 \%)$ & $0.209(-16 \%)$ \\
\hline & & Spring & 0.324 & $0.355(9 \%)$ & $0.321(-1 \%)$ & $0.269(-17 \%)$ \\
\hline \multirow[t]{6}{*}{ MAB } & \multirow[t]{2}{*}{ Ice area $\left(10^{6} \mathrm{~km}^{2}\right)$} & Annual & 0.365 & $\mathbf{0 . 1 5 0}(-\mathbf{5 9} \%)$ & $0.109(-70 \%)$ & $0.130(-64 \%)$ \\
\hline & & Spring & 0.551 & $0.269(-51 \%)$ & $0.194(-65 \%)$ & $0.241(-56 \%)$ \\
\hline & \multirow[t]{2}{*}{ Ice volume $\left(10^{3} \mathrm{~km}^{3}\right)$} & Annual & 0.991 & $0.622(-37 \%)$ & $0.232(-77 \%)$ & $0.507(-49 \%)$ \\
\hline & & Spring & 1.477 & $1.053(-29 \%)$ & $0.242(-84 \%)$ & $0.641(-57 \%)$ \\
\hline & \multirow[t]{2}{*}{ Snow volume $\left(10^{3} \mathrm{~km}^{3}\right)$} & Annual & 0.211 & $0.216(2 \%)$ & $0.197(-7 \%)$ & $0.172(-18 \%)$ \\
\hline & & Spring & 0.319 & $0.353(10 \%)$ & $0.319(0 \%)$ & $0.267(-16 \%)$ \\
\hline
\end{tabular}

Results for snow volume are mixed. As shown in Fig. 6c, DA does not influence snow volume in the melting season (roughly from May to September) and has relatively larger impacts in the accumulation season (roughly from October to April), which is opposite to the updates exerted on sea ice area by DA (Fig. 6a). Among all the cases, DA_SIC_MYI has the largest influence on snow volume. Since snowfall starts earlier than sea ice advances, the alreadyexisting multiyear sea ice can capture more snow than first-year sea ice. Hence, compared with other observations, MYI is more related to snow volume.

Table 3 summarizes the IIEE, RMSE, and MAB of the total Arctic sea ice area, sea ice volume, and snow volume for FREE and the DA experiments. Experiment DA_SIC can effectively remove errors of the total Arctic sea ice area by about $60 \%$ annually and by about $50 \%$ in the spring months (April-May). Sea ice extent error as measured by IIEE is reduced by $28 \%$ annually and $22 \%$ in spring. The total Arctic sea ice volume error is reduced by $37 \%$ annually and around $30 \%$ in spring. Experiment DA_SIC_SIT can further improve the total Arctic ice area but not ice extent. SIT is significantly improved, with error reduced by more than $70 \%$ annually and more than $80 \%$ in spring. Experiment DA_SIC_MYI slightly improves ice area over DA_SIC. It improves ice volume fairly well with an approximately $50 \%$ error reduction. Experiment DA_SIC_MYI is able to decrease the SNO error by about $16 \%$, while DA_SIC and DA_SIC_SIT have no obvious influence on SNO.

\section{c. Further discussion on localization half-width}

We demonstrated that a small localization is necessary in order to optimize the performance of SIC data assimilation. The same localization half-width of $0.01 \mathrm{rad}$ is utilized for the multivariate DA experiments. However, different observed quantities may have different correlation length scales. For example, SIT very likely has a much larger correlation length than SIC (Blanchard-Wrigglesworth and Bitz 2014). To examine the influence of different localization distances on SIT assimilation, we run additional DA experiments assimilating SIT only for the year 2001 with different localization half-widths: DA_SIT_LOC0.01 $(0.01 \mathrm{rad})$, DA_SIT_LOC0.05 (0.05 rad), and DA_SIT_ LOC0.1 ( $0.1 \mathrm{rad})$. Figure 8 suggests that larger localization half-widths work better for SIT assimilation. The fact that most differences in SIC reside along the ice edges (Fig. 8a) is very likely because DA_SIT_LOC0.01 has already removed most of the SIC errors in the central Arctic. As a contrast, there are still remaining errors in SIT in the central Arctic, and hence SIT is improved a lot when larger localization half-width is applied (Fig. 8b). Experiments DA_SIT_LOC0.05 and DA_SIT_LOC0.1 also have smaller IIEE, RMSE, and MAB of the total Arctic sea ice area, ice volume, and snow volume than DA_SIT_LOC0.01. Compared to DA_SIT_LOC0.01, they can reduce RMSE and $\mathrm{MAB}$ of ice area and volume by more than $50 \%$. Since 


\section{DA_SIT_LOC0.05 - DA_SIT_LOC0.01 DA_SIT_LOC0.1 - DA_SIT_LOC0.01}
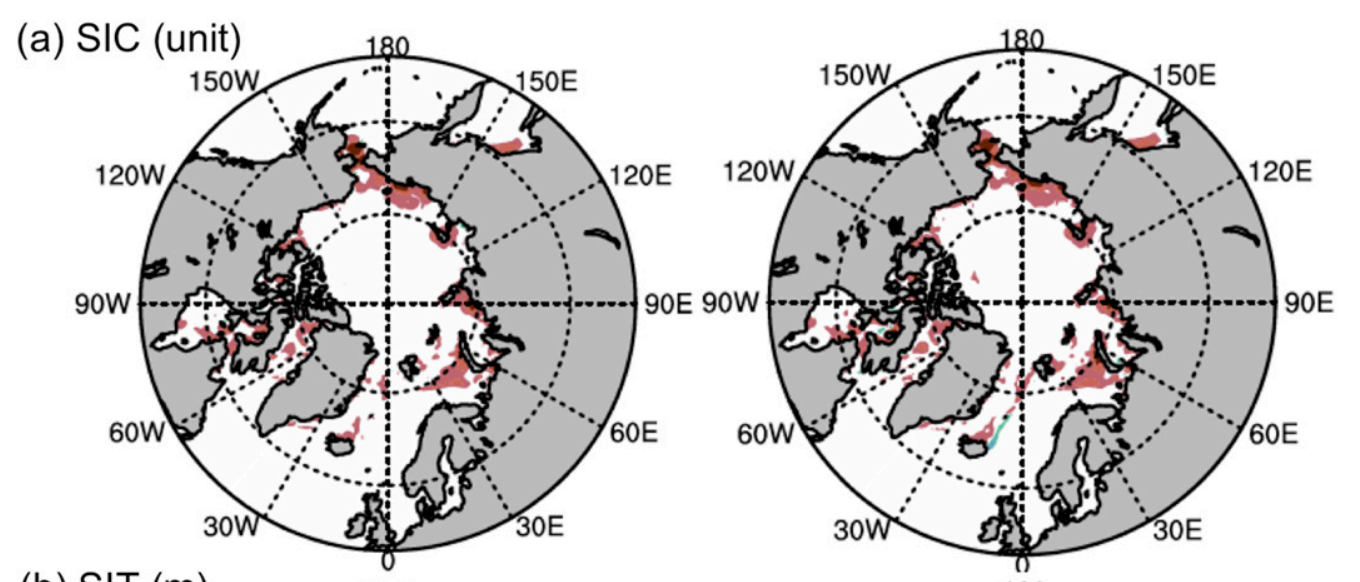

(b) SIT (m)

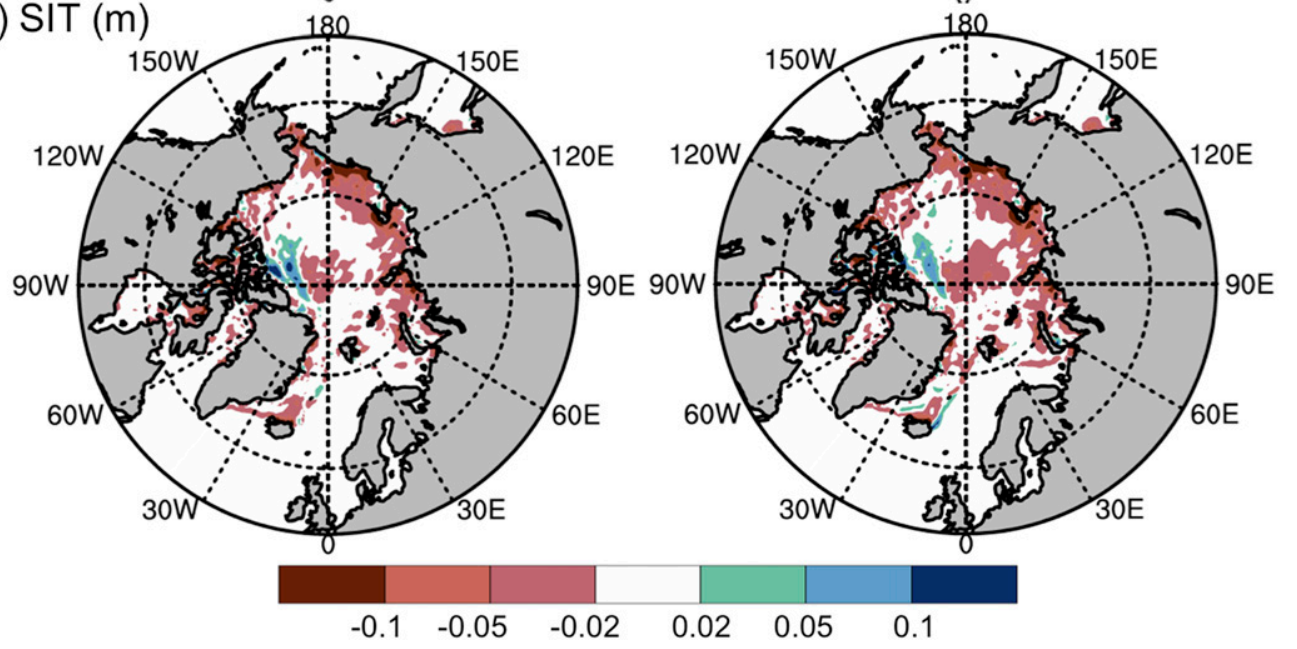

FIG. 8. RMSE of (a) SIC and (b) SIT for (left) DA_SIT_LOC0.05 minus DA_SIT_LOC0.01 and (right) DA_SIT_ LOC0.1 minus DA_SIT_LOC0.01. Negative values indicate larger localization distances work better, while positive values indicate smaller localization distances work better. Daily model output in 2001 is used to calculate RMSE.

DA_SIT_LOC0.01 has already removed most of the errors, further reducing the residual errors may seem insignificant, but this is not the case with the absence of a dense SIT observation network. Observations of SIT are usually sparse in space and time in reality and hence applying a larger localization distance will make a greater difference.

\section{Conclusions}

We linked CICE5, the sea ice component of CESM, with DART to develop a sea ice data assimilation (DA) system that is capable of assimilating multivariate observations and exploring various ensemble DA options. We designed a series of perfect model observing system simulation experiments (OSSEs) to demonstrate the functionality of the DA system, to explore the optimal use of sea ice concentration (SIC) observations, and to test the relative importance of different observation types for improving sea ice analysis.
Assimilation of SIC observations can significantly reduce the SIC error but not necessarily the area biases of individual categories, that is, the ice thickness distribution. A small localization distance is required in order to improve the ice thickness distribution, which suggests SIC has a small correlation length scale. Adaptive approaches for localization should be followed more systematically. Performance of DA also depends on how we postprocess the model states. Updating sea ice volume as the product of the posterior ice area and the prior ice thickness is a better choice than directly updating sea ice volume through the EnKF. Overall, the best SIC DA case could improve the simulations of sea ice thickness (SIT) but mostly in the marginal sea ice zone.

Assimilating other important observation types will further improve simulations of the Arctic ice pack in different ways. The joint assimilation of SIC and SIT produces the best results for SIC and SIT. The improvements are large for 
the whole Arctic. Multiyear ice concentration (MYI) is a good substitute for SIT. Assimilating MYI and SIC together has a fairly good performance in SIT both temporally and spatially. It is worth noting that MYI and SIT are strongly correlated with sea ice concentration of individual categories in the interior Arctic sea ice pack, so assimilating them leads to improved estimates in the interior Arctic, where SIC observations alone are unable to improve the state.

We also suggest that it is more effective to use a different localization for each type of observation-state variable pair. For example, a small localization halfwidth is optimal for the pair of SIC and aicen, while a larger localization half-width performs better for the pair of SIT and aicen. This could be explained by the different spatial correlation length scales of SIC and SIT.

Acknowledgments. This work was supported by NOAA Grant CPO NA15OAR4310161. We thank Adrian Raftery and Hannah Director for helpful discussions, and David Bailey and Marika Holland for suggestions about running the CICE5 model. François Massonnet is an F.R.S.-FNRS Postdoctoral Fellow. We acknowledge CISL at the National Center for Atmospheric Sciences and TACC at The University of Texas at Austin for providing HPC resources that have contributed to the research results reported within the paper.

\section{REFERENCES}

Anderson, J. L., 2001: An ensemble adjustment Kalman filter for data assimilation. Mon. Wea. Rev., 129, 2884-2903, https:// doi.org/10.1175/1520-0493(2001)129<2884:AEAKFF>2.0.CO;2. , 2007a: Exploring the need for localization in ensemble data assimilation using a hierarchical ensemble filter. Physica $D, 230,99$ 111, https://doi.org/10.1016/j.physd.2006.02.011.

- , 2007b: An adaptive covariance inflation error correction algorithm for ensemble filters. Tellus, 59A, 210-224, https:// doi.org/10.1111/j.1600-0870.2006.00216.x.

_ the nonlinear filtering problem to produce ensemble assimilations and forecasts. Mon. Wea. Rev., 127, 2741-2758, https://doi.org/ 10.1175/1520-0493(1999)127<2741:AMCIOT>2.0.CO;2.

-, T. Hoar, K. Raeder, H. Liu, N. Collins, R. Torn, and A. Arellano, 2009: The Data Assimilation Research Testbed: A community facility. Bull. Amer. Meteor. Soc., 90, 1283-1296, https://doi.org/10.1175/2009BAMS2618.1.

Belchansky, G. I., D. C. Douglas, I. V. Alpatsky, and N. G. Platonov, 2004: Spatial and temporal multiyear sea ice distributions in the Arctic: A neural network analysis of SMM/I data, 1988-2001. J. Geophys. Res., 109, C10017, https://doi.org/ 10.1029/2004JC002388.

Blanchard-Wrigglesworth, E., and C. M. Bitz, 2014: Characteristics of Arctic sea-ice thickness variability in GCMs. J. Climate, 27, 8244-8258, https://doi.org/10.1175/JCLI-D-14-00345.1.

, K. C. Armour, C. M. Bitz, and E. deWeaver, 2011a: Persistence and inherent predictability of Arctic sea ice in a GCM ensemble and observations. J. Climate, 24, 231-250, https:// doi.org/10.1175/2010JCLI3775.1.
_ C. M. Bitz, and M. M. Holland, 2011b: Influence of initial conditions and climate forcing on predicting Arctic sea ice. Geophys. Res. Lett., 38, L18503, https://doi.org/10.1029/2011GL048807.

Bushuk, M., R. Msadek, M. Winton, G. A. Vecchi, R. Gudgel, A. Rosati, and X. Yang, 2017: Skillful regional prediction of Arctic sea ice on seasonal timescales. Geophys. Res. Lett., 44, 4953-4964, https://doi.org/10.1002/2017GL073155.

Chen, Z., J. Liu, M. Song, Q. Yang, and S. Xu, 2017: Impacts of assimilating satellite sea ice concentration and thickness on Arctic sea ice prediction in the NCEP Climate Forecast System. J. Climate, 30, 8429-8446, https://doi.org/10.1175/JCLI-D-17-0093.1.

Chevallier, M., D. Salas y Mélia, A. Voldoire, M. Déqué, and G. Garric, 2013: Seasonal forecasts of the pan-Arctic sea ice extent using a GCM-based seasonal prediction system. J. Climate, 26, 6092-6104, https://doi.org/10.1175/JCLI-D-12-00612.1.

Collow, T. W., W. Wang, A. Kumar, and J. Zhang, 2015: Improving Arctic sea ice prediction using PIOMAS initial sea ice thickness in a coupled ocean-atmosphere model. Mon. Wea. Rev., 143, 4618-4630, https://doi.org/10.1175/MWR-D-15-0097.1.

Comiso, J. C., 2002: A rapidly declining perennial sea ice cover in the Arctic. Geophys. Res. Lett., 29, 1956, https://doi.org/10.1029/ 2002GL015650.

, 2012: Large decadal decline of the Arctic multiyear ice cover. J. Climate, 25, 1176-1193, https://doi.org/10.1175/ JCLI-D-11-00113.1.

$\longrightarrow$, C. L. Parkinson, R. Gersten, and L. Stock, 2008: Accelerated decline in the Arctic sea ice cover. Geophys. Res. Lett., 35, L01703, https://doi.org/10.1029/2007GL031972.

Danabasoglu, G., S. C. Bates, B. P. Briegleb, S. R. Jayne, M. Jochum, W. G. Large, S. Peacock, and S. G. Yeager, 2012: The CCSM4 ocean component. J. Climate, 25, 1361-1389, https://doi.org/10.1175/JCLI-D-11-00091.1.

Day, J. J., S. Tietsche, and E. Hawkins, 2014a: Pan-Arctic and regional sea ice predictability: Initialization month dependence. J. Climate, 27, 4371-4390, https://doi.org/10.1175/ JCLI-D-13-00614.1.

—, E. Hawkins, and S. Tietsche, 2014b: Will Arctic sea ice thickness initialization improve seasonal forecast skill? Geophys. Res. Lett., 41, 7566-7575, https://doi.org/10.1002/ 2014GL061694.

Dirkson, A., W. J. Merryfield, and A. Monahan, 2017: Impacts of sea ice thickness initialization on seasonal Arctic sea ice predictions. J. Climate, 30, 1001-1017, https://doi.org/10.1175/ JCLI-D-16-0437.1.

Evensen, G., 1992: Using the extended Kalman filter with a multilayer quasi-geostrophic ocean model. J. Geophys. Res., 97, 17 905-17 924, https://doi.org/10.1029/92JC01972.

, 1994: Sequential data assimilation with a nonlinear quasigeostrophic model using Monte Carlo methods to forecast error statistics. J. Geophys. Res., 99, 10143-10162, https://doi.org/10.1029/94JC00572.

, 2003: The ensemble Kalman filter: Theoretical formulation and practical implementation. Ocean Dyn., 53, 343-367, https://doi.org/10.1007/s10236-003-0036-9.

Gaspari, G., and S. E. Cohn, 1999: Construction of correlation functions in two and three dimensions. Quart. J. Roy. Meteor. Soc., 125, 723-757, https://doi.org/10.1002/qj.49712555417.

Goessling, H. F., S. Tietsche, J. J. Day, E. Hawkins, and T. Jung, 2016: Predictability of the Arctic sea ice edge. Geophys. Res. Lett., 43, 1642-1650, https://doi.org/10.1002/2015GL067232.

Holland, M. M., C. M. Bitz, and B. Tremblay, 2006: Future abrupt reductions in the summer Arctic sea ice. Geophys. Res. Lett., 33, L23503, https://doi.org/10.1029/2006GL028024. 
Hunke, E. C., W. H. Lipscomb, A. K. Turner, N. Jeffery, and S. Elliott, 2015: CICE: The Los Alamos Sea Ice Model documentation and software user's manual, version 5.1. Los Alamos National Laboratory Doc. LA-CC-06-012, 116 pp.

Kaleschke, L., and Coauthors, 2016: SMOS sea ice product: Operational application and validation in the Barents Sea marginal ice zone. Remote Sens. Environ., 180, 264-273, https:// doi.org/10.1016/j.rse.2016.03.009.

Kalnay, E., 2002: Atmospheric Modeling, Data Assimilation and Predictability. Cambridge University Press, 342 pp.

Kimmritz, M., F. Counillon, C.M. Bitz, F. Massonnet, I. Bethke, and Y. Gao, 2018: Optimising assimilation of sea ice concentration in an Earth system model with a multicategory sea ice model. Tellus, 70A, 1435945, https://doi.org/10.1080/16000870.2018.1435945.

Kurtz, N. T., and S. L. Farrell, 2011: Large-scale surveys of snow depth on Arctic sea ice from Operation IceBridge. Geophys. Res. Lett., 38, L20505, https://doi.org/10.1029/2011GL049216.

Kwok, R., 2004: Annual cycles of multiyear sea ice coverage of the Arctic Ocean: 1999-2003. J. Geophys. Res., 109, C11004, https://doi.org/10.1029/2003JC002238.

— Estimation of snow depth and ice thickness. J. Geophys. Res., 113, C08010, https://doi.org/10.1029/2008JC004753.

— , and D. A. Rothrock, 2009: Decline in Arctic sea ice thickness from submarine and ICESat records: 1958-2008. Geophys. Res. Lett., 36, L15501, https://doi.org/10.1029/2009GL039035.

Lindsay, R. W., and J. Zhang, 2006: Assimilation of ice concentration in an ice-ocean model. J. Atmos. Oceanic Technol., 23, 742-749, https://doi.org/10.1175/JTECH1871.1.

Lisæter, K. A., J. Rosanova, and G. Evensen, 2003: Assimilation of ice concentration in a coupled ice-ocean model, using the ensemble Kalman filter. Ocean Dyn., 53, 368-388, https:// doi.org/10.1007/s10236-003-0049-4.

Lukovich, J. V., and D. G. Barber, 2007: On the spatiotemporal behavior of sea ice concentration anomalies in the Northern Hemisphere. J. Geophys. Res., 112, D13117, https://doi.org/ 10.1029/2006JD007836.

Maslanik, J. A., C. Fowler, J. Stroeve, S. Drobot, J. Zwally, D. Yi, and W. Emery, 2007: A younger, thinner Arctic ice cover: Increased potential for rapid, extensive sea-ice loss. Geophys. Res. Lett., 34, L24501, https://doi.org/10.1029/2007GL032043.

Massonnet, F., T. Fichefet, and H. Goosse, 2015: Prospects for improved seasonal Arctic sea ice predictions from multivariate data assimilation. Ocean Modell., 88, 16-25, https://doi.org/ 10.1016/j.ocemod.2014.12.013

Meier, W. N., 2005: Comparison of passive microwave ice concentration algorithm retrievals with AVHRR imagery in the Arctic peripheral seas. IEEE Trans. Geosci. Remote Sens., 43, 1324-1337, https://doi.org/10.1109/TGRS.2005.846151.

- J. Stroeve, and F. Fetterer, 2007: Whither Arctic sea ice? A clear signal of decline regionally, seasonally and extending beyond the satellite record. Ann. Glaciol., 46, 428-434, https:// doi.org/10.3189/172756407782871170.

Msadek, R., G. A. Vecchi, M. Winton, and R. G. Gudgel, 2014: Importance of initial conditions in seasonal predictions of Arctic sea ice extent. Geophys. Res. Lett., 41, 5208-5215, https://doi.org/10.1002/2014GL060799.

Mu, L., Q. Yang, M. Losch, S. N. Losa, R. Ricker, L. Nerger, and X. Liang, 2017: Improving sea ice thickness estimates by assimilating CryoSat-2 and SMOS sea ice thickness data simultaneously. Quart. J. Roy. Meteor. Soc., 144, 529-538, https:// doi.org/10.1002/qj.3225.
Nghiem, S. V., Y. Chao, G. Neumann, P. Li, D. K. Perovich, T. Street, and P. Clemente-Colón, 2006: Depletion of perennial sea ice in the east Arctic Ocean. Geophys. Res. Lett., 33, L17501, https://doi.org/10.1029/2006GL027198.

Po-Chedley, S., K. C. Armour, C. M. Bitz, M. D. Zelinka, B. D. Santer, and Q. Fu, 2018: Sources of intermodel spread in the lapse rate and water vapor feedbacks. J. Climate, 31, 31873206, https://doi.org/10.1175/JCLI-D-17-0674.1.

Raeder, K., J. L. Anderson, N. Collins, T. J. Hoar, J. E. Kay, P. H. Lauritzen, and R. Pincus, 2012: DART/CAM: An ensemble data assimilation system for CESM atmospheric models. J. Climate, 25, 6304-6317, https://doi.org/10.1175/JCLI-D-11-00395.1.

Screen, J. A., and I. Simmonds, 2010: The central role of diminishing sea ice in recent Arctic temperature amplification. Nature, 464, 1334-1337, https://doi.org/10.1038/nature09051.

Serreze, M. C., M. M. Holland, and J. Stroeve, 2007: Perspectives on the Arctic's shrinking sea-ice cover. Science, 315, 15331536, https://doi.org/10.1126/science.1139426.

Stroeve, J. C., V. Kattsov, A. Barrett, M. Serreze, T. Pavlova, M. Holland, and W. N. Meier, 2012: Trends in Arctic sea ice extent from CMIP5, CMIP3 and observations. Geophys. Res. Lett., 39, L16502, https://doi.org/10.1029/2012GL052676.

Tian-Kunze, X., L. Kaleschke, N. Maaß, M. Mäkynen, N. Serra, M. Drusch, and T. Krumpen, 2014: SMOS-derived thin sea ice thickness: Algorithm baseline, product specifications and initial verification. Cryosphere, 8, 997-1018, https://doi.org/ 10.5194/tc-8-997-2014.

Tilling, R. L., A. Ridout, and A. Shepherd, 2016: Near-real-time Arctic sea ice thickness and volume from CryoSat-2. Cryosphere, 10, 2003-2012, https://doi.org/10.5194/tc-10-2003-2016.

Urrego-Blanco, J. R., N. M. Urban, E. C. Hunke, A. K. Turner, and N. Jeffery, 2016: Uncertainty quantification and global sensitivity analysis of the Los Alamos Sea Ice Model. J. Geophys. Res. Oceans, 121, 2709-2732, https://doi.org/ 10.1002/2015JC011558.

Whitaker, J. S., and T. M. Hamill, 2012: Evaluating methods to account for system errors in ensemble data assimilation. Mon. Wea. Rev., 140, 3078-3089, https://doi.org/10.1175/MWR-D-11-00276.1.

Yang, Q., S. N. Losa, M. Losch, X. Tian-Kunze, L. Nerger, J. Liu, L. Kaleschke, and Z. Zhang, 2014: Assimilating SMOS sea ice thickness into a coupled ice-ocean model using a local SEIK filter. J. Geophys. Res. Oceans, 119, 6680-6692, https://doi.org/ 10.1002/2014JC009963.

,,--- T. Jung, and L. Nerger, 2015: The role of atmospheric uncertainty in Arctic summer sea ice data assimilation and prediction. Quart. J. Roy. Meteor. Soc., 141, 2314-2323, https://doi.org/10.1002/qj.2523.

— M. Losch, S. N. Losa, T. Jung, L. Nerger, and T. Lavergne, 2016a: Brief communication: The challenge and benefit of using sea ice concentration satellite data products with uncertainty estimates in summer sea ice data assimilation. Cryosphere, 10, 761-774, https://doi.org/10.5194/tc-10-761-2016.

,,,$--- \ldots$, and,$- 2016 \mathrm{~b}$ : Taking into account atmospheric uncertainty improves sequential assimilation of SMOS sea ice thickness data in an ice-ocean model. J. Atmos. Oceanic Technol., 33, 397-407, https://doi.org/10.1175/ JTECH-D-15-0176.1.

Zhang, Y.-F., T. J. Hoar, Z.-L. Yang, J. L. Anderson, A. M. Toure, and M. Rodell, 2014: Assimilation of MODIS snow cover through the Data Assimilation Research Testbed and the Community Land Model version 4. J. Geophys. Res. Atmos., 119, 7091-7103, https://doi.org/10.1002/2013JD021329. 